\title{
PLURALIDAD DE SUJETOS EN LA RELACIÓN JURÍDICO-HIPOTECARIA ${ }^{1}$
}

\author{
BEATRIZ SÁENZ DE JUBERA HIGUERO \\ Becaria de FPU. Área de Derecho Civil \\ Departamento de Derecho. Universidad de La Rioja
}

\begin{abstract}
SUMARIO
I. INTRODUCCIÓN. II. MODOS DE ARTICULARSE LA PLURALIDAD EN LA RELACIÓN JURÍDICO-HIPOTECARIA. III. REFLEJO DE LA PLURALIDAD DE SUJETOS EN EL REGISTRO DE LA PROPIEDAD. IV. PLURALIDAD DE HIPOTECANTES Y/O TERCEROS POSEEDORES. V. PLURALIDAD DE ACREEDORES HIPOTECARIOS. 1. Cotitularidad en mano común. 2. Cotitularidad solidaria. 3. Cotitularidad mancomunada o parciaria. VI. PLURALIDAD DE DEUDORES. 1. otitularidad en mano común. 2. Cotitularidad solidaria. 3. Cotitularidad mancomunada o parciaria. VII. CONCLUSIÓN.
\end{abstract}

\section{RESUMEN}

La realidad jurídico-hipotecaria es bastante compleja; y lo es aún más cuando en las distintas posiciones jurídicas concurre una pluralidad de sujetos. Hay que tener en cuenta los dos tipos de relaciones jurídicas que conviven en estas situaciones: una obligacional (que une al acreedor o acreedores con el deudor o deudores) y otra real (que vincula al acreedor o acreedores con el hipotecante o hipotecantes o, en su caso, los terceros poseedores). De cada una de estas situaciones hay que respetar su naturaleza y régimen esenciales y sus principios rectores y tratar de armonizarlos entre sí. De esta forma se podrán determinar las posibilidades de actuación eficaz de cada uno de los sujetos, especialmente en la fase de exigencia del crédito o cumplimiento de la prestación

\footnotetext{
${ }^{1}$ Este trabajo supone la reproducción parcial del trabajo de investigación que, en el marco del Programa de Doctorado impartido durante el curso 2001/2002 en el Departamento de Derecho de la Universidad de La Rioja, se sometió el 18 de junio de 2002 a la valoración del Tribunal nombrado a tal efecto, obteniendo la calificación de sobresaliente.
} 


\section{INTRODUCCIÓN.}

En la relación jurídico-hipotecaria nos podemos encontrar con las siguientes situaciones de cotitularidad, que también pueden aparecer combinadas:

- Pluralidad activa o de acreedores hipotecarios. Es la que más discusiones doctrinales y resoluciones judiciales y de la DGRN ha suscitado.

- Pluralidad de hipotecantes o, en su caso, terceros poseedores adquirentes del bien gravado.

- Pluralidad de deudores. Esta circunstancia puede quedar cubierta por una situación de pluralidad de hipotecantes en caso de que el deudor hipoteque un bien propio.

Resulta de alto interés práctico analizar las posibilidades de actuación de los distintos sujetos y, especialmente, los efectos que esa conducta tendrá sobre la hipoteca y en el Registro. Si bien son muchos los supuestos y actos en los que es interesante este análisis, en este trabajo me he centrado en la fase de ejecución, de cumplimiento y exigencia de la prestación.

En cualquiera de las tres situaciones hay que tener en cuenta los principios de accesoriedad, indivisibilidad y especialidad, que pueden verse afectados por la división del crédito o la deuda entre distintos sujetos o por la posibilidad de ejercicio individual de las acciones correspondientes.

En este caso, ante la indivisibilidad del derecho de hipoteca ex art. $1.860 \mathrm{CC}$, ¿cabe una actuación individual de cada sujeto o todos deben proceder conjuntamente?; si se admite la actuación individual, ¿en qué medida afectará la misma al resto de cotitulares y a la propia existencia de la hipoteca?.

Tales interrogantes son prácticamente los mismos que surgen en caso de pluralidad subjetiva en las obligaciones en general. Por tanto, habrá que atender al modo en que puede organizarse esa cotitularidad (parciariedad, solidaridad, en mano común) y, en su caso, al plano de las relaciones internas y externas (a este plano será al que afecte más la hipoteca) entre los sujetos. Si bien ahora también habrá que prestar atención a la influencia de los principios mencionados (indivisibilidad, especialidad y accesoriedad).

Estas situaciones complejas pueden ponerse de manifiesto a priori, en el momento de constitución de la hipoteca, o a posteriori, tras dicha constitución a través, por ejemplo, de una cesión parcial o una subrogación parcial en el crédito, o por la transmisión total o parcial del bien hipotecado a distintos sujetos o por novación de la posición deudora ${ }^{2}$.

\footnotetext{
${ }^{2}$ En cuanto a la cesión del crédito a varios sujetos o la cesión parcial, es interesante la clasificación que AZPiTARTE CAMY hace de las situaciones resultantes (vid. AZPitARTE CAMY, Rafael: "Cesión parcial y pluralidad de acreedores en los créditos hipotecarios" en Libro-homenaje a Juan Manuel Rey Portolés, Centro de Estudios Registrales, Madrid, 1998, p. 334-335). Según este autor habría que distinguir entre:
} 
Si la pluralidad es originaria, nos podremos encontrar con criterios convencionales de solución para eventuales problemas o dificultades que puedan surgir; criterios que en el momento de la inscripción de la hipoteca habrán sido controlados por el Registrador.

Sin embargo, si la pluralidad es sobrevenida, probablemente tales pactos no existirán.

En consecuencia, ¿qué régimen aplicaremos en caso de pluralidad sobrevenida o de pluralidad originaria en la que o no se haya previsto nada por las partes o lo pactado no sea suficiente por no atender a todas las vicisitudes?. Las normas y criterios relativos a estos supuestos contenidos en el Código civil y en la Ley y Reglamento hipotecarios son escasos. Se acoge un modelo de relación jurídico-hipotecaria partiendo de la unipersonalidad en las distintas posiciones subjetivas y, por tanto, no se presta atención a los diferentes modos de organizarse la pluralidad ${ }^{3}$.

No existe un determinado régimen legal supletorio para estos casos. Por tanto, habrá que acudir a las normas generales sobre cotitularidad jurídico-obligacional (arts. 1.137 ss CC) y sobre la comunidad (arts. 392 ss CC), con las oportunas adaptaciones cuando la pluralidad se proyecta sobre un derecho indivisible como es la hipoteca.

Tal solución no está exenta de dificultades en cuanto se acude, en palabras de VERDERA SERVER, a "criterios que, o presuponen una relación meramente jurídicoobligacional, o prescinden de la conexión entre situación jurídico-real y derecho de crédito"4.

\section{II.- MODOS DE ARTICULARSE LA PLURALIDAD EN LA RELACIÓN JURÍDICO-HIPOTECARIA.}

Entre las distintas formas en que puede organizarse una situación subjetivamente compleja en este ámbito, nos fijaremos únicamente en las siguientes: en mano común, mancomunidad o parciariedad y solidaridad.

En virtud del principio de accesoriedad, la pluralidad en la hipoteca seguiría la configuración que existe en la obligación o crédito garantizado ${ }^{5}$.

- Cesión que provoca situación de cotitularidad. No se divide el objeto del crédito y se transfieren o retienen cuotas indivisas del mismo; es decir, facultades idénticas a las del crédito total, y, por tanto, facultades sustancialmente iguales para todos los acreedores, aunque cuantitativamente sean desiguales.

- Cesión que provoca situación de titularidad compartida. Aquí sí se divide materialmente el objeto del crédito, o su aprovechamiento económico, y se transfieren o retienen partes de dicho objeto que se fracciona y que, por tanto, son cualitativamente diferentes.

${ }^{3}$ Vid. Verdera SERVER, Rafael: La hipoteca a favor de dos o más acreedores (Cotitularidad crediticia y garantía hipotecaria), Tirant lo Blanch, Valencia, 1999, p. 13 ss.

${ }^{4}$ Verdera SERVER, Rafael: La hipoteca a favor de dos o más acreedores..., op. cit., p. 32.

${ }^{5}$ Vid. AzPITARTE CAMY, Rafael: "Cesión parcial y pluralidad de acreedores en los créditos hipotecarios", op. cit., p. 377 y CORDERO LOBATO, Encarna: "Obligaciones asegurables con Hipoteca Inmobiliaria: requisitos generales y modalidades", en CARRASCO PERERA, Ángel [et. al.]: Tratado de los Derechos de Garantía, Aranzadi, 2002, p. 530-531.

Por otro lado, como opinión aislada en nuestra doctrina, cabe señalar la sostenida por PEÑA BERNALDO DE QUIRÓS, que se basa en la total independencia del crédito y la hipoteca y en el carácter indivisible de esta última. Afirma que, a pesar de la accesoriedad de la hipoteca respecto del crédito, la 
Ahora bien, según BLASCO GASCÓ ${ }^{6}$, cabe que las partes o cotitulares pacten una ordenación distinta, aunque habría que tener en cuenta ciertas incompatibilidades derivadas de los principios de especialidad y accesoriedad.

Así, este autor entiende que tanto si la relación jurídico-obligacional se configura en régimen de solidaridad como en mano común, los acreedores hipotecarios podrían ordenar tal cotitularidad en la hipoteca indistintamente como solidaridad o bajo el régimen de las obligaciones en mano común, actuando siempre colectivamente. Pero no cabría configurar la relación jurídico-hipotecaria como parciaria en estos casos salvo que haya distribución del crédito. La parciariedad en la hipoteca existirá siempre que en la relación obligatoria se acoja ese régimen.

\section{III.- REFLEJO DE LA PLURALIDAD DE SUJETOS EN EL REGISTRO DE LA PROPIEDAD.}

Sobre esta cuestión, si bien con referencia únicamente a la pluralidad activa o de acreedores hipotecarios, se han pronunciado tanto la DGRN como la doctrina.

Así, pues, la DGRN, en sus Resoluciones de 28 de julio de 1998, de 23 de marzo de 1994 y de 1 de marzo de 1994 (además de las que en ellas se citan), pone de manifiesto la necesidad de especificar en el asiento registral el carácter solidario o mancomunado de la cotitularidad en el derecho, y, en este último caso, la concreta cuota del crédito garantizado que corresponde a cada acreedor de modo que quede debidamente precisada la extensión y alcance del derecho inscrito, "sin que sea suficiente [...] la mera presunción de igualdad derivada de los artículos 393 y 1.138 del Código Civil, presunción que en modo alguno define, dado su carácter de tal (vid. artículo 1.251 del Código Civil) la verdadera extensión del derecho de cada acreedor". Tal determinación precisa e inequívoca del contenido y extensión de los derechos que pretenden su acceso al Registro es exigida "a fin de facilitar la fluidez y seguridad de su tráfico jurídico" y en desenvolvimiento del principio de especialidad previsto en los arts. 9, 11 y $12 \mathrm{LH}$ y 51 y 54 RH (RDGRN de 23 de marzo de 1994).

Respecto de los créditos solidarios, la DGRN (entre otras, en su Resolución de 15 de febrero de 2000) no exige la determinación de la participación de cada acreedor en el mismo. Esas cuotas pertenecen al ámbito de las relaciones internas y quedan al margen del Registro y de la hipoteca, así como del deudor y los terceros que adquieran derechos sobre el bien hipotecado? .

hipoteca es un derecho distinto y además indivisible, por lo que, ante la pluralidad subjetiva cualquiera que sea su ordenación, el ejercicio de las acciones hipotecarias se deberá hacer conjuntamente por todos los acreedores: vid. PeÑa Bernaldo De QuiRós, M.: Derechos reales. Derecho hipotecario, $2^{\text {a }}$ edición, Universidad de Madrid, Facultad de Derecho, Sección de Publicaciones, Madrid, 1986, p. 483 (citado por AZPITARTE CAMY, Rafael: "Cesión parcial y pluralidad de acreedores en los créditos hipotecarios", op. cit., p. 349).

${ }^{6}$ Blasco Gascó, Francisco de Paula: La hipoteca inmobiliaria y el crédito hipotecario, Tirant lo Blanch, Valencia, 2000, p. 92 ss.

${ }^{7}$ Vid. VERDERA SERVER, Rafael: La hipoteca a favor de dos o más acreedores..., op. cit., p. 68-70 y CORDERO LOBATO, Encarna: “Obligaciones asegurables con Hipoteca Inmobiliaria: requisitos generales y modalidades”, en CARrasco PERERA, Ángel [et. al.]: Tratado de los Derechos de Garantía, op. cit., p. $530-531$. 
A pesar de la aparente claridad con la que se expresa la DGRN en estas Resoluciones, en nuestra doctrina se ha discutido la necesidad de que se hagan constar las cuotas específicas de los acreedores en los créditos solidarios y en los créditos en mano común.

Para ROCA SASTRE "no es preciso este requisito, a base de que en estos casos no existen cuotas o porciones ideales, a las que se refiere el art. $54 \mathrm{RH}$, y de que las citadas Resoluciones se produjeron frente a supuestos de obligaciones mancomunadas

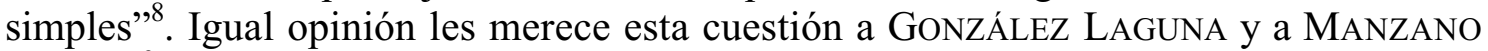
SOLANO ${ }^{9}$.

BALLARÍN MARCIAL ${ }^{10}$, por su parte, considera que la especificación de las cuotas en caso de créditos solidarios puede resultar conveniente pero no es indispensable.

Sin embargo, AzPITARTE CAMY ${ }^{11}$ cree necesaria esa constancia registral de las cuotas en el crédito solidario y BLASCO GASCÓ ${ }^{12}$ lo exige para los supuestos de créditos en mano común, constituidos en comunidad romana u ordinaria.

Estas Resoluciones se refieren a las cotitularidades constituidas originariamente pero no se pronuncian acerca de las sobrevenidas. Al no condicionar la DGRN la posible aplicación del art. $54 \mathrm{RH}$ al carácter originario o sobrevenido de la pluralidad, parece que lo señalado en esas Resoluciones cabe aplicarlo a ambos casos ${ }^{13}$.

En cuanto al reflejo en el Registro de la Propiedad de las otras dos posibles situaciones de cotitularidad con que nos podemos encontrar, se puede señalar que, por lo que respecta a la pluralidad de hipotecantes o de terceros poseedores, esta cotitularidad se pondrá de manifiesto en el correspondiente asiento en que se refleje que el bien hipotecado es propiedad de varios sujetos (ya sean éstos quienes los hipotecan ya sean los que los hayan adquirido tras la constitución de la hipoteca).

Respecto a la pluralidad pasiva, también será necesario, en virtud del principio de especialidad o determinación (art. 9 LH), que en la inscripción se haga constar el carácter solidario o mancomunado de la deuda y, en este último caso, señalar asimismo

\footnotetext{
${ }^{8}$ Roca SAStre, Ramón Ma y Roca-SASTRE Muncunill, Luis: Derecho Hipotecario, tomo VIII, Hipotecas, $8^{\text {a }}$ edición, Bosch, Barcelona, 1998, p. 285.

${ }^{9}$ Vid. GonzÁlez Laguna, Miguel y Manzano Solano, Antonio: "Algunos problemas actuales de la hipoteca a la luz de sus principios históricos”, RCDI, núm. 566, enero-febrero, 1985, p. 209.

${ }^{10}$ BALLARÍN MARCIAL, Alberto: "Titularidad solidaria" (conferencia pronunciada en la Academia Matritense del Notariado el día 9 de diciembre de 1958), AAMN, tomo III, Madrid, 1962, p. 205.

${ }^{11}$ Vid. AzPITARTE CAMY, Rafael: "Cesión parcial y pluralidad de acreedores en los créditos hipotecarios", op. cit., p. 372. De la misma opinión son GARCÍA GARCÍA, J. M.: El procedimiento judicial sumario de ejecución de hipoteca, Civitas, Madrid, 1994, p. 115 y PEÑA BERNALDO DE QUIRÓs, M.: Derechos reales. Derecho hipotecario, $2^{\text {a }}$ edición, Universidad de Madrid, Facultad de Derecho, Sección de Publicaciones, Madrid, 1986, p. 483-484 (ambos citados por VERDERA SERVER, Rafael: La hipoteca a favor de dos o más acreedores..., op. cit., p. 79 y 82-83). Estos autores afirman que la solidaridad se referiría al crédito o derecho obligacional y no a la hipoteca; a la hora de inscribir habría que señalarse las cuotas de cada acreedor en el crédito pues al considerarse la hipoteca como un derecho real, no puede pertenecer solidariamente a varias personas.

${ }^{12}$ Vid. Blasco GASCÓ, Francisco de Paula: La hipoteca inmobiliaria y el crédito hipotecario, op. cit., p. 93.

${ }^{13}$ Vid. VERDERA SERVER, Rafael: La hipoteca a favor de dos o más acreedores..., op. cit., p. 71.
} 
la cuota de participación de cada deudor en la deuda garantizada con la hipoteca (aplicación analógica del art. $54 \mathrm{RH})^{14}$.

Tanto en el caso de que la situación subjetivamente compleja tenga lugar en la posición activa como en la pasiva, lo que, a mi juicio, sí sería relevante es precisar en el Registro los distintos plazos o condiciones afectantes a cada sujeto, en el caso de que se haya constituido una solidaridad no uniforme ex art. 1.140 CC.

Por otro lado, ante una hipoteca de seguridad, en concreto de máximo (en la que la cuantía de la deuda o crédito garantizado no está perfectamente determinada sino que simplemente se ha señalado un máximo), las cuotas de participación que deben especificarse en la inscripción de la hipoteca en el Registro en caso de mancomunidad, vendrán referidas a ese importe máximo ${ }^{15}$.

\section{PLURALIDAD DE HIPOTECANTES Y/O TERCEROS POSEEDORES}

La cotitularidad en el derecho de propiedad sobre el bien o los bienes hipotecados da lugar a un régimen de comunidad de bienes, regulado en los arts. 392-406 CC, aunque sobre tal situación entra en juego en primer lugar la autonomía de la voluntad (art. $1.255 \mathrm{CC}$ ) a través de los contratos, pactos o convenios celebrados entre los comuneros $^{16}$.

Esta situación se manifestará no sólo respecto de los varios hipotecantes sino también en el caso de que el bien gravado se enajene totalmente a varios sujetos (terceros poseedores adquirentes de la finca hipotecada) o bien se enajene la cuota de uno de los comuneros a una persona ajena a la comunidad.

Nuestro Código civil acoge el sistema de organización de la comunidad romana. Como consecuencia de considerar la situación de comunidad como algo desventajoso, se da preferencia a los propios sujetos, concediéndoles derechos exclusivos sobre una determinada cuota o parte del bien común y reconociéndoles la facultad de pedir la división y salir de la comunidad.

Respecto de la cuota singular cada comunero tiene plena disposición, teniendo facultad para enajenarla y constituir un gravamen sobre ella. Los efectos de tal actuación en relación a los demás condueños estarán limitados a la porción que se le adjudique en la división al cesar la comunidad (art. 399 CC).

Cada sujeto participará en los beneficios y cargas en proporción a las cuotas que tengan, que, salvo prueba en contrario, se presumen iguales (art. 393 CC). Las cuotas

${ }^{14}$ Vid. Roca SAStre, Ramón M $\mathrm{M}^{\mathrm{a}}$ y RocA-SAstre Muncunill, Luis: Derecho Hipotecario, tomo VIII, Hipotecas, op. cit., p. 266 y CORDERO LOBATO, Encarna: “Obligaciones asegurables con Hipoteca Inmobiliaria: requisitos generales y modalidades", en CARRASCO PERERA, Ángel [et. al.]: Tratado de los Derechos de Garantía, op. cit., p. 531.

15 Vid. CORdero Lobato, Encarna: "Vencimiento y ejecución de la hipoteca inmobiliaria", en CARrasco Perera, Ángel [et. al.]: Tratado de los Derechos de Garantía, op. cit., p. 723.

${ }^{16}$ El art. 392 CC señala: "Hay comunidad cuando la propiedad de una cosa o de un derecho pertenece pro indiviso a varias personas. A falta de contratos, o de disposiciones especiales, se regirá la comunidad por las prescripciones de este título [Título III del Libro II]". 
serán también las que se tengan en cuenta a la hora de computar la mayoría necesaria para decidir los actos de administración y mejor disfrute de la cosa común (art. 398 $\mathrm{CC})$.

Respecto de la cosa común, cada partícipe podrá servirse de la misma, pero siempre conforme a su destino y sin perjudicar a la comunidad ni al ejercicio de los demás comuneros (art. $394 \mathrm{CC}$ ).

Por su parte, el art. 397 CC dispone:

"Ninguno de los condueños podrá, sin consentimiento de los demás, hacer alteraciones en la cosa común, aunque de ellas pudieran resultar ventajas para todos".

Por lo tanto, la decisión de constituir un gravamen como la hipoteca sobre el bien común debe ser unánime, pues ello conlleva una alteración del régimen de la comunidad. De igual modo en el caso de enajenación total del bien, aun después de constituir la hipoteca ${ }^{17}$.

La existencia de pluralidad de hipotecantes o terceros poseedores constituidos en régimen de comunidad de bienes tiene incidencia en la relación jurídico-hipotecaria únicamente en la medida en que la decisión de constituir la hipoteca y la de enajenar el bien gravado exige la decisión unánime de todos, así como en el hecho de que serán varios los sujetos que puedan sufrir las consecuencias del impago del crédito garantizado, al ver ejecutada la hipoteca sobre sus bienes; serán varios los que tengan que acudir al proceso ejecutivo, judicial (arts. 681 ss LEC) o extrajudicial (arts. 234 ss $\mathrm{RH})$, como propietarios hipotecantes o terceros adquirentes del bien hipotecado.

Ahora bien, puede darse el caso de que la pluralidad de hipotecantes o terceros poseedores se corresponda con la existencia de una pluralidad de bienes hipotecados, de manera que entre los sujetos no exista comunidad sino que sean cada uno propietario de uno de los bienes gravados ${ }^{18}$.

En este caso, habría que atender a los arts. 119-125 LH que acogen la regulación de los supuestos en que existe pluralidad de bienes hipotecados, exigiéndose, en virtud del principio de especialidad registral, la determinación en el Registro de la Propiedad de la parte de responsabilidad hipotecaria que cada bien deba soportar ${ }^{19}$.

El art. 119 LH dispone:

"Cuando se hipotequen varias fincas a la vez por un solo crédito, se determinará la cantidad o parte de gravamen de que cada una deba responder".

${ }^{17}$ Vid. DíEz-PiCAzo, Luis y Gullón, Antonio: Sistema de Derecho Civil, volumen III, Derecho de cosas y Derecho Inmobiliario Registral, $7^{\text {a }}$ edición, Tecnos, Madrid, 2001, p. 72 ss.

${ }^{18}$ Cabría también la existencia de comunidad entre alguno de los sujetos sobre uno o varios bienes y además que los demás sean únicos titulares individuales del resto de los bienes hipotecados. En este caso, las incidencias vendrían determinadas conforme a lo que se indica para cada una de las situaciones.

${ }^{19}$ Esta distribución del crédito entre las distintas fincas hipotecadas, según el art. 216 RH, se realizará mediante convenio entre las partes (en el mismo título de constitución de hipoteca o en otro documento público o en solicitud dirigida al Registrador firmada o ratificada ante él o cuyas firmas estén legitimadas) o mandato judicial. 
De esta manera, a la hora de adquirir uno de los bienes hipotecados se sabe con certeza cuál es la cantidad por la que responde el mismo y, en consecuencia, por la que puede ser ejecutado. El tercer poseedor adquirente del bien sólo sufrirá, en su caso, la ejecución de la hipoteca por el importe de la responsabilidad fijada registralmente desde el principio. Más allá de esa cantidad el tercero es inmune a la prelación crediticia determinada por la hipoteca (cfr. arts. 120 y $121 \mathrm{LH}$ ).

Por su parte, el art. $123 \mathrm{LH}$, en su primer párrafo, señala que cuando la pluralidad objetiva es sobrevenida, como consecuencia de la división de la finca hipotecada en varias, para que exista distribución de la responsabilidad hipotecaria deben acordarla el acreedor y el deudor. El acreedor está, en este caso, renunciando a la indivisibilidad de la hipoteca.

Es como si existieran tantas hipotecas como bienes, aunque, eso sí, respecto de cada bien y la parte de crédito a él asignada, la hipoteca mantiene su típico carácter indivisible ${ }^{20}$.

Ahora bien, en caso de que esa distribución del crédito entre los distintos bienes no se lleve a cabo, cualquiera de los varios titulares podrá ver ejecutado su concreto bien por la totalidad del crédito garantizado (art. $123 \mathrm{LH}$ ), tal y como si existiera una solidaridad pasiva (cfr. art. 1.144 CC).

Del mismo modo, en caso de pago total (evitando la ejecución o a través de la ejecución misma), ese hipotecante no deudor o tercer poseedor adquirente del bien hipotecado se subrogará, ex arts. 1.210, apartado tercero, y $1.212 \mathrm{CC}$, en todos los derechos y privilegios con los que contaba el acreedor frente al deudor. Igualmente podrá dirigirse contra los demás hipotecantes o terceros poseedores, pero no por la totalidad de la deuda, sino sólo proporcionalmente (cfr. arts. 1.145, segundo párrafo, y $1.844 \mathrm{CC}$, respecto de los cuales se procede a su aplicación analógica) ${ }^{21}$.

Por otro lado, el art. 124 LH prevé la posibilidad de, una vez realizada esa distribución de la responsabilidad hipotecaria entre las varias fincas, cancelar parcialmente la hipoteca en cuanto afecte a un determinado bien si se paga la cantidad del crédito afectante a la misma y así se exige "por aquél a quien interese".

Esta es una regla excepcional, atendiendo al carácter indivisible de la hipoteca (art. $1.860 \mathrm{CC}$ ) y a la no obligación del acreedor a admitir pagos parciales (art. 1.169 CC).

${ }^{20}$ Vid. CORDERo LoBATO, Encarna: "El objeto de la Hipoteca Inmobiliaria", en CARRASCO PERERA, Ángel [et. al.]: Tratado de los Derechos de Garantía, op. cit., p. 510.

${ }^{21}$ Por supuesto, en caso de que entre los hipotecantes se encuentre el deudor, si éste es el que al final paga al ejecutarse su finca o antes, no podrá ir contra ninguno de los demás hipotecantes o terceros poseedores, por ser todos ellos extraños a la obligación garantizada.

Respecto a la posibilidad de que el hipotecante no deudor se subrogue en los derechos del acreedor, el Tribunal Supremo (en, entre otras, la STS de 23 de marzo de 2000) se muestra contrario, a diferencia de un amplio sector de la doctrina. Cfr. BERCOVITZ RodRíGUEZ-Cano, Rodrigo: "Ejecución hipotecaria: acciones del poseedor del bien hipotecado (tercero hipotecante) frente al deudor y frente a fiadores solidarios del deudor (Comentario a la sentencia de 23 de marzo de 2000)", CCJC, 2000, núm. 53, p. 879-887; Cordero LOBATO, Encarna: "El objeto de la Hipoteca Inmobiliaria", en CARRASCO PERERA, Ángel [et. al.]: Tratado de los Derechos de Garantía, op. cit., p. 510-511; y PANTALEÓn PRIETO, Fernando: "Diálogo sobre las desventuras jurisprudenciales del «fiador hipotecario»", Diario La Ley, 2002, núm. 5.537, p. 1-5. 
Así pues, si el acreedor hipotecario acepta el cumplimiento parcial podrá pedirse esa cancelación parcial. Ahora bien, no podrá negarse al pago parcial si el que lo realiza es un tercer poseedor del bien hipotecado, no subrogado en el crédito (cfr. art. 221 $\mathrm{RH})^{22}$.

\section{PLURALIDAD DE ACREEDORES HIPOTECARIOS}

En este trabajo me centraré en los supuestos de pluralidad de acreedores hipotecarios en una misma relación jurídica, dejando, en principio, a un lado los supuestos en los que existe pluralidad de acreedores pero también de créditos garantizados (como cuando se constituyen por una misma persona distintas hipotecas en garantía de diferentes créditos o un deudor garantiza con una sola hipoteca varios créditos pertenecientes a personas distintas ${ }^{23}$ ).

\section{Cotitularidad en mano común.}

Esta forma de ordenación de la pluralidad subjetiva es, en principio, extraña a nuestro ordenamiento, aunque sus mismos efectos y régimen se reconocen a los supuestos de obligaciones mancomunadas con objeto indivisible (art. 1.139 CC). Asimismo, podría surgir esta configuración en virtud de la autonomía privada ex art. $1.255 \mathrm{CC}$.

En estos casos, al igual que en el crédito, se atribuye la titularidad de la hipoteca a todos, como si fueran una única persona.

Este tipo de cotitularidad exige que los acreedores actúen conjuntamente ${ }^{24}$. Por lo tanto, todos deberán decidir y ejercitar las acciones tendentes a la conservación de su derecho y de los bienes sobre los que recae (como la acción de devastación del art. 117 LH) en la llamada fase de seguridad de la hipoteca; todos deberán acordar la cesión del crédito hipotecario; todos ejecutarán, llegado el momento, la hipoteca a través de la oportuna acción real hipotecaria y todos cancelarán totalmente la hipoteca en el Registro.

El problema surgirá cuando alguno de los acreedores se niegue a actuar; problema, por otro lado, propio de este tipo de configuración de las obligaciones; no específico de los supuestos en que existe una hipoteca que garantiza el cumplimiento de esa obligación.

\footnotetext{
${ }^{22}$ Vid. DíEz-PiCAZO, Luis y Gullón, Antonio: Sistema de Derecho Civil, volumen III, ..., op. cit., p. 448-449.

${ }^{23}$ La DGRN rechaza, con base en el principio de especialidad, la constitución de una hipoteca única unitaria para garantizar créditos totalmente independientes entre sí, pero admite, ex arts. 227 y $241 \mathrm{RH}$, la constitución de varias hipotecas en garantía de distintas obligaciones pactándose la igualdad de rango. Vid. Verdera Server, Rafael: La hipoteca a favor de dos o más acreedores..., op. cit., p. 15 ss y BLASCO GASCÓ, Francisco de Paula: La hipoteca inmobiliaria y el crédito hipotecario, op. cit., p. 91.

${ }^{24}$ Vid., entre otros, RocA SASTRE, Ramón $\mathrm{M}^{\mathrm{a}}$ y ROCA-SASTRE MunCuniLl, Luis: Derecho Hipotecario, tomo VIII, Hipotecas, op. cit., p. 277 y 285.
} 
En este caso, y aplicando la normativa civil sobre la comunidad de bienes, podría entenderse que la postura del sujeto no actuante supone un perjuicio para la comunidad y el resto de cotitulares al impedir, además, el uso del bien o derecho común (la hipoteca) conforme al destino propio del mismo (la garantía del crédito y, en su caso, su ejecución) (art. 394 CC). En consecuencia, podría exigirse la división de la hipoteca común y la configuración como parciaria (arts. 400-402 CC) ${ }^{25}$.

\section{Cotitularidad solidaria.}

Los créditos solidarios se caracterizan por el reconocimiento a cada acreedor de la facultad para actuar individualmente exigiendo la total prestación con eficacia para todos.

Además, puede apreciarse la existencia de dos niveles: el de las relaciones externas (las que vinculan a acreedores y deudores $\mathrm{y} / \mathrm{o}$, en el ámbito hipotecario, los hipotecantes) y el de las relaciones internas (que surgen entre los varios acreedores, y es donde se determinan las posibles responsabilidades de cada uno, rindiendo cuentas de su actuación).

En el crédito garantizado con hipoteca nos encontramos con idéntica situación.

En primer lugar, atendiendo exclusivamente a la relación obligatoria existente entre los acreedores y el único deudor (hipotecante o no), hay que señalar que la existencia de solidaridad activa supone la aplicación del régimen típico de esta clase de obligaciones (arts. 1.137 ss CC).

El deudor tiene la facultad de elegir al acreedor a quien pagar, una vez haya vencido la obligación, en principio, y siempre que no haya sido demandado judicialmente por uno de los acreedores (cfr. art. 1.142 CC). Ante el pago plenamente liberatorio de la deuda, la obligación se extingue y se producirá la rendición de cuentas entre los acreedores en la dimensión interna. Además, no se ejecutará la hipoteca y habrá que proceder a su cancelación.

En cuanto a los acreedores, cada uno individualmente podrá realizar cualquiera de los actos previstos en los arts. 1.141 y 1.143 CC (interrupción de prescripción, creación de gravámenes como la hipoteca, novación, compensación...), atendiendo a la armonización que desde la doctrina se hace de estos dos preceptos ${ }^{26}$.

Por supuesto, cada uno podrá decidir acudir a la acción personal o a la acción real hipotecaria para cobrar el crédito total. Claramente la decisión de ejercitar la acción personal puede considerarse un acto perjudicial para los demás acreedores, pues

25 Vid. CORDERo Lobato, Encarna: "Vencimiento y ejecución de la hipoteca inmobiliaria", en CARrasco PererA, Ángel [et. al.]: Tratado de los Derechos de Garantía, op. cit., p. 723.

${ }^{26}$ Cfr., entre otros, CRISTÓBAL MONTES, Ángel: La estructura y los sujetos de la obligación, Civitas, Madrid, 1990, p. 282 ss; GuILARTE ZAPATERO, Vicente: "Comentario de los arts. 1.137 a 1.148 CC" en Comentarios al Código Civil y Compilaciones Forales, Artículos 1.125 a 1.155 del Código Civil, dirigidos por Manuel ALBALADEJO, tomo XV, volumen 2, EDERSA, Madrid, 1983, p. 265 ss; DíEz-PICAZO, Luis: Fundamentos de Derecho Civil Patrimonial, II. Las relaciones obligatorias, $4^{\text {a }}$ edición, Civitas, Madrid, 1993, p. 189 ss; y BALlarín MARCIAL, Alberto: “Titularidad solidaria”, op. cit., p. 187 ss. 
conlleva un mayor riesgo para el cobro que el ejercicio de la acción real hipotecaria (una acción que supone la sujeción del bien gravado a la satisfacción preferente de su crédito respecto de los demás posibles acreedores). Pero ese posible perjuicio se dirimirá en las relaciones internas.

Respecto a la relación jurídico-hipotecaria, hay que apuntar la existencia de una sola hipoteca de la que todos son titulares y respecto a la cual cada acreedor puede actuar individualmente, produciendo tal conducta eficacia respecto de los demás acreedores (se ejecutará la totalidad de la hipoteca, a pesar del ejercicio de la acción por un solo acreedor).

Esa actuación individual puede hacerse efectiva en cualquiera de las dos fases de la hipoteca: tanto en la fase de seguridad (por ejemplo, a través del ejercicio de la acción de devastación) como en la de ejecución o de realización del valor (ejercicio de la acción real, ejecución de la hipoteca, cancelación de la misma...), sin perjuicio de la responsabilidad que se dirimirá en la relación interna (cfr. arts. 1.141 y 1.143 CC).

Sin embargo, hay quien no está de acuerdo con esa posibilidad de ejercicio individual de un acreedor solidario con efectos para todos en el ámbito de un crédito hipotecario, fundamentalmente con base en la exigibilidad de determinar las cuotas de cada acreedor solidario en el crédito garantizado, la indivisibilidad de la hipoteca y la necesidad de distinguir entre el plano sustantivo obligacional y el plano registral ${ }^{27}$.

Frente a esta postura cabe alegar que el régimen de las obligaciones solidarias recogido en el Código civil no aparece excepcionado para los supuestos en que el crédito está garantizado con una hipoteca. La hipoteca no puede suponer la disminución de facultades del acreedor solidario ni la alteración esencial del régimen de tal ordenación de la cotitularidad querida por las partes, sobre todo, si se atiende al carácter accesorio de la hipoteca respecto del crédito ${ }^{28}$.

También existe controversia acerca de la posibilidad de que un solo acreedor cancele totalmente la hipoteca para todos.

Hay quien señala que no debe admitirse, no sólo porque afirman la imposibilidad de ejercicio individual de la acción real hipotecaria, sino también acudiendo a la

${ }^{27}$ Vid. GARCía GARCÍA, J. M.: El procedimiento judicial sumario de ejecución de hipoteca, Civitas, Madrid, 1994, p. 115 y PEÑA BERnAldo DE QuIRÓS, M.: Derechos reales. Derecho hipotecario, $2^{\mathrm{a}}$ edición, Universidad de Madrid, Facultad de Derecho, Sección de Publicaciones, Madrid, 1986, p. 483484 (ambos citados por VERDERA SERVER, Rafael: La hipoteca a favor de dos o más acreedores..., op. cit., p. 79 y 82-83). Estos autores afirman la exigibilidad de la determinación registral de las cuotas de participación en el crédito garantizado, aun siendo de carácter solidario. Propugnan la conveniencia de distinguir entre plano sustantivo y plano registral. En este último ámbito, la solidaridad se referiría al crédito o derecho obligacional y no a la hipoteca. Según estos autores, a la hora de inscribir habría que señalarse las cuotas de cada acreedor en el crédito pues al considerarse la hipoteca como un derecho real, no puede pertenecer solidariamente a varias personas.

${ }^{28}$ Vid. VERDERA SERVER, Rafael: La hipoteca a favor de dos o más acreedores..., op. cit., p. 80 ss y AZPITARTE CAMY, Rafael: "Cesión parcial y pluralidad de acreedores en los créditos hipotecarios", op. cit., p. 370. 
prohibición de los actos perjudiciales ex art. $1.141 \mathrm{CC}$, lo que supondría exigir para la cancelación de la hipoteca el consentimiento de todos ${ }^{29}$.

Pero si atendemos a la doctrina dominante que armoniza este art. $1.141 \mathrm{CC}$ con el art. 1.143 CC, en el sentido de limitar la eficacia del art. 1.141 CC a la relación interna de los acreedores, sí debiera admitirse esa posibilidad de cancelación individual, dejando que se dirima la posible responsabilidad para con el resto de coacreedores en las relaciones internas ${ }^{30}$.

Los posibles perjuicios para los acreedores no actuantes que se derivarían del ejercicio individual de la acción real hipotecaria y la posterior cancelación de la garantía, en cuanto al riesgo de no verse satisfechos en su parte del crédito (argumento de los que niegan la posibilidad de cancelación total unilateral) son efectos propios de la existencia de la solidaridad, ya sea en un crédito ordinario o en un crédito hipotecario.

Esta nota de "peligrosidad" es lo que ha hecho de la solidaridad activa una figura poco atractiva y que en la práctica se limite a supuestos en los que entre los acreedores existan vínculos estrechos o de confianza y tengan suficiente solvencia patrimonial ${ }^{31}$.

Cuestión distinta e interesante es qué ocurre ante una solidaridad activa no uniforme en la que existen distintos plazos de vencimiento afectantes a los diversos sujetos.

En este caso, como en cualquier otro crédito en estas circunstancias, el acreedor vinculado puramente o al que primero ha sobrevenido el vencimiento de la obligación no podrá reclamar los derechos afectados por plazos o condiciones especiales. Así que, si le reclama todo al deudor, éste podrá oponerle una excepción derivada de la aplicación analógica y armónica del primer inciso del art. 1.148 CC a estos supuestos de solidaridad activa.

Pero si sólo le reclama su parte vencida y esa parte no es cumplida ¿cabría ejecutar la hipoteca?; y esa ejecución ¿sería total o parcial?.

En mi opinión, sí cabría ejecutar la hipoteca, pues está se constituyó para garantizar a los acreedores solidarios el cobro del crédito total, y una vez que la obligación vence y no se cumple voluntariamente entra en juego la vía de ejecución de la hipoteca. El acreedor que primero ve vencida la obligación no tiene por qué esperar a los demás

${ }^{29}$ Vid. GARcía GARCÍA, J. M.: El procedimiento judicial sumario de ejecución de hipoteca, Civitas, Madrid, 1994, p. 115 y PEÑA BERnAldo DE QuiRós, M.: Derechos reales. Derecho hipotecario, $2^{\text {a }}$ edición, Universidad de Madrid, Facultad de Derecho, Sección de Publicaciones, Madrid, 1986, p. 484 (ambos citados por VERDERA SERVER, Rafael: La hipoteca a favor de dos o más acreedores..., op. cit., p. 83).

${ }^{30}$ Vid. DíEz-PiCAzO, Luis: Fundamentos de Derecho Civil Patrimonial, II..., op. cit., p. 189; Guilarte ZAPATERO, Vicente: "Comentario de los arts. 1.137 a 1.148 CC", op. cit., p. 266; CristÓBAL MONTES, Ángel: La estructura y los sujetos de la obligación, op. cit., p. 291; BALlARín MARCIAL, Alberto: "Titularidad solidaria", op. cit., p. 204-205; AZPITARTE CAMY, Rafael: "Cesión parcial y pluralidad de acreedores en los créditos hipotecarios", op. cit., p. 371-372; y RoCA SASTRE, Ramón Ma y RocA-SASTRE Muncunill, Luis: Derecho Hipotecario, tomo VIII, Hipotecas, op. cit., p. 285.

${ }^{31}$ Vid. AzPITARTE CAMY, Rafael: "Cesión parcial y pluralidad de acreedores en los créditos hipotecarios", op. cit., p. 367. 
cotitulares para poder actuar, pues ello sería contradictorio con la propia esencia de la solidaridad (cfr. arts. 1.137, 1.141 y 1.143 CC).

Así, en este caso, se ejecutará la garantía, pero sólo por el importe del crédito vencido y, por tanto, exigible ${ }^{32}$.

Tal ejecución no se llevará a cabo si, tras el requerimiento previsto en el art. 686 LEC, en el momento de despachar la ejecución y antes de proceder a la subasta, el deudor, el hipotecante o los terceros poseedores requeridos pagan la deuda.

Pero, tanto se pague antes de la subasta como si se llega a ella, lo pagado o lo obtenido en el remate beneficiará a todos los acreedores.

Ahora bien, ese importe no puede imputarse a su concreta cuota pues, a pesar de la no uniformidad, seguimos estando ante una obligación solidaria y no parciaria, de modo que el acreedor actuante sigue siendo acreedor del resto de la obligación.

Eso sí, el importe del crédito se verá reducido, lo que se hará constar por nota marginal a la inscripción hipotecaria (art. 240, último inciso, RH). Pero la hipoteca permanecerá íntegra sobre el bien o bienes gravados, en virtud de los arts. 1.860 CC y 122 ss LH.

\section{Cotitularidad mancomunada o parciaria.}

Esta articulación de la pluralidad subjetiva, que en nuestro ordenamiento se presume a falta de previsión expresa de la solidaridad (art. $1.138 \mathrm{CC}$ ), supone que el crédito se divide en tantas partes como acreedores existan, "reputándose créditos distintos unos de otros" (art. 1.138 CC).

La cuestión fundamental en caso de créditos parciarios garantizados con hipoteca es cómo armonizar esa división del crédito en varios autónomos entre sí y el carácter indivisible de la garantía.

En estos supuestos, ¿también hay que considerar dividida la hipoteca en tantas partes como acreedores y créditos parciarios existan, lo que llevará a reconocer la posibilidad de ejercicio individual de la acción hipotecaria, con eficacia meramente parcial?, ¿o hay que entender que en estos casos se debe exigir la actuación conjunta de la acción hipotecaria en virtud de la indivisibilidad de la hipoteca?; ese eventual ejercicio aislado de la acción real hipotecaria, ¿debe motivar la subsistencia de la hipoteca a favor de los demás acreedores o debe suponer la cancelación total, para todos, de la garantía?.

Lo que hay que tener claro es que hay que deslindar perfectamente dos cuestiones: la posibilidad o no de ejercicio individual de la acción hipotecaria por cada acreedor parciario; y, por otro lado, la eficacia parcial o total de esa actuación individual en cuanto a la hipoteca, es decir, su cancelación parcial o total.

\footnotetext{
${ }^{32}$ En caso de que, tras haberse despachado la ejecución, venciere la obligación para otros acreedores, podrá ampliarse la ejecución en virtud del art. 578 LEC.
} 
Como señala VERDERA SERVER "negar la eficacia total de una actuación individual en caso de crédito parciario no significa necesariamente exigir siempre una actuación conjunta (que obviamente dará lugar a una eficacia total). El conflicto se plantea en relación a la admisión y al alcance de la actuación singular". En los supuestos de crédito solidario o en mano común cabe hablar de cancelación total, pero no con los créditos mancomunados, pues "una actuación individual con eficacia total contradice los principios de la cotitularidad parciaria",33.

Este ha sido un tema sobre el que han surgido distintas y controvertidas opiniones, apoyadas en el distinto alcance otorgado por cada autor a los principios de indivisibilidad y accesoriedad de la hipoteca respecto del crédito.

Las distintas teorías han surgido, fundamentalmente, a raíz de la STS de 10 de marzo de 1947, que niega la posibilidad de ejercicio individual de la acción hipotecaria por la determinada cuota creditual del acreedor actuante, precisamente por el carácter indivisible de esta garantía real.

Unos se muestran favorables a la doctrina de esta sentencia. Entienden que la admisión de la actuación individual sería un sistema especialmente gravoso para el dueño de la finca que soportaría una pluralidad de ejecuciones (tantas como coacreedores haya) y sería insatisfactoria para el primer coacreedor que ejecuta si el valor de la finca es insuficiente (este primer acreedor sufriría mayor riesgo) ${ }^{34}$.

A esto cabría oponer el hecho de que ese riesgo lo sufren todos los acreedores y que un mismo sujeto no sufre una pluralidad de ejecuciones, pues tras la primera de ellas el adquirente del bien en la subasta será quien sufra la siguiente ejecución parcial, y así cada vez que se ejecute el bien hipotecado ${ }^{35}$.

Estos autores consideran que hay que diferenciar ejercicio del derecho de crédito (que se regiría por la normativa general del Código civil: arts. $1.137 \mathrm{ss)} \mathrm{y} \mathrm{ejercicio} \mathrm{de} \mathrm{la}$ acción hipotecaria (respecto del que no cabría la actuación individual).

Representante de esta teoría es PEÑA BERNALDo DE QUIRÓs ${ }^{36}$, para el cual es preferible la aplicación del régimen de la comunidad: la actuación deberá ser conjunta o bien individual pero en beneficio de todos, procediendo a la consignación del importe obtenido. Lleva el principio de indivisibilidad hasta sus últimas consecuencias sin atender al principio de accesoriedad.

Para otros, también se exige la actuación conjunta, pero no con base en las normas de la comunidad de bienes sino en el art. 1.139 CC (régimen de las obligaciones

${ }^{33}$ VERDERA SERVER, Rafael: La hipoteca a favor de dos o más acreedores..., op. cit., p. 107-108.

${ }^{34}$ Vid. PEÑA BeRnAldo DE QUIRÓs, Manuel: Derechos reales. Derecho Hipotecario, tomo II, Derechos reales de garantía. Registro de la Propiedad, $3^{\text {a }}$ edición, Centro de Estudios Registrales, Madrid, 1999, p. 275.

35 Vid. CORDERo LobAto, Encarna: "Vencimiento y ejecución de la hipoteca inmobiliaria", en CARrasco Perera, Ángel [et. al.]: Tratado de los Derechos de Garantía, op. cit., p. 722.

${ }^{36}$ Vid. PEÑA BERnALdo DE QuiRÓs, Manuel: Derechos reales. Derecho Hipotecario,..., op. cit., p. 275. De igual opinión es NúÑEZ IGLESIAS, Álvaro: Comunidad e indivisibilidad, McGraw-Hill, Madrid, 1995, p. 242-243.

AZPITARTE CAMY denomina a esta postura: "teoría de la hipoteca conjunta" (vid. AzPITARTE CAMY, Rafael: “Cesión parcial y pluralidad de acreedores en los créditos hipotecarios”, op. cit., p. 348). 
mancomunadas indivisibles). Consideran esencial tanto el principio de indivisibilidad como el de accesoriedad y configuran el crédito hipotecario con dos tipos de prestaciones: unas divisibles (las que nacen del propio crédito) y otras indivisibles (nacen de la hipoteca y se rigen por el art. $1.139 \mathrm{CC})^{37}$.

GARCÍA GARCÍA considera preciso distinguir entre pluralidad activa originaria y sobrevenida. Mientras que en el primer caso sí cabría la ejecución parcial e individual de la hipoteca, en el segundo no sería posible por impedirlo el art. $1.860 \mathrm{CC}$, siendo necesaria la actuación conjunta ${ }^{38}$.

Otros son más críticos con lo dictado por el Tribunal Supremo en la citada sentencia y estiman que debe admitirse la actuación individual.

Entienden que la sentencia dota de un valor desorbitado al principio de indivisibilidad. Consideran esencial el carácter accesorio de la hipoteca respecto del crédito y dotan al principio de indivisibilidad de un sentido no tan radical ${ }^{39}$.

La idea de cuota en el crédito se aplicaría también a la hipoteca; la pluralidad de sujetos activos en la misma llevaría a constituir tantas hipotecas como acreedores o una sola hipoteca dividida en tantas cuotas como acreedores hipotecarios existan, pudiendo cada acreedor ejercitar de modo autónomo la acción hipotecaria con eficacia parcial.

Avalaría tal postura la exigencia por parte de la DGRN (cfr. RRDGRN de 1 de marzo de 1994 y 23 de marzo de 1994, entre otras) y del art. 54 RH de que se determine en el título la cuota o participación de cada acreedor en el crédito garantizado.

Además, alegan, aunque se reputen distintas, cada cuota nace y forma parte de una misma hipoteca y, en consecuencia, deben tener el mismo rango, siéndoles aplicable el art. 227 RH. De igual modo, si se determinase la constitución de tantas hipotecas distintas como acreedores, podría pactarse la igualdad de rango y serles aplicable también el art. $227 \mathrm{RH}$.

Este precepto, introducido por la reforma de 1947 (posterior a la sentencia), haría insostenible la doctrina de la STS de 10 de marzo de 1947, al consagrar la regla de ejercicio aislado por cualquiera de los acreedores parciarios sin perjuicio para los demás, pues en garantía de sus créditos queda subsistente la hipoteca. Esta norma llenaría la laguna legal que se denunciaba en la sentencia y que motivó su pronunciamiento $^{40}$.

${ }^{37}$ Vid. AzPITARTE CAMY, Rafael: "Cesión parcial y pluralidad de acreedores en los créditos hipotecarios", op. cit., p. 348; LÓPEZ TORRES, José Ma: "Créditos hipotecarios del mismo rango", RCDI, junio 1943, núm. 181, p. 361 ss y LANA SANCHÍs, Emilio: "Ensayo sobre créditos hipotecarios de igual rango o simultáneos", RCDI, diciembre1943, núm. 187, p. 834 ss.

${ }^{38}$ Vid. GARCÍA GARCÍA, J. M.: El procedimiento judicial sumario de ejecución de hipoteca, Civitas, Madrid, 1994, p. 112 ss (citado por AZPITARTE CAMY, Rafael: "Cesión parcial y pluralidad de acreedores en los créditos hipotecarios", op. cit., p. 350-351).

${ }^{39}$ Esta teoría, cuyo mayor exponente lo encontramos en las personas de Ramón M ${ }^{\text {a }}$ ROCA SASTRE y Luis ROCA-SASTRE MUNCUNILL, ha sido denominada por AZPITARTE CAMY "teoría de la hipoteca por cuotas de actuación autónoma", tanto en el crédito como en la hipoteca (vid. AZPITARTE CAMY, Rafael: "Cesión parcial y pluralidad de acreedores en los créditos hipotecarios", op. cit., p. 348). 
Estos autores tienen razón al señalar que, de no admitirse la posibilidad de actuación individual y exigirse la conjunta, se estaría desvirtuando el régimen de la cotitularidad parciaria, pues la existencia de la hipoteca conllevaría siempre la aplicación del régimen de las obligaciones en mano común. Asimismo se llegaría a una situación en la que no sería interesante acudir a la constitución de hipoteca pues la misma perjudicaría a los acreedores parciarios al limitar sus posibilidades de actuación y satisfacción de su derecho respecto de las que tendrían con el ejercicio de la acción personal (total independencia y autonomía en la reclamación de su parte en el crédito) ${ }^{41}$.

Ciertamente no hay que olvidar que nos encontramos ante un crédito que, por voluntad de las partes, se ha configurado mancomunadamente. En consecuencia, la intención de las partes es que se mantengan indemnes las posibilidades de actuación aislada de cada uno por su parte, pues de lo contrario se hubiera pactado la solidaridad o la articulación en mano común. Debe mantenerse el criterio de la existencia de tantos créditos como acreedores parciarios.

Al existir la hipoteca, y en virtud de la regla de accesoriedad de la misma respecto del crédito, puede decirse que igualmente existirán tantas hipotecas o cuotas de la hipoteca como créditos y que, además, disfrutarán de un mismo rango según el art. 227 RH.

Cada acreedor podrá ejercitar su derecho con total independencia de los demás y, en consecuencia, ante el incumplimiento voluntario de la prestación podrá acudir a la ejecución de la hipoteca respecto a su parte, subsistiendo el gravamen sobre el mismo o los mismos bienes a favor de los demás acreedores (art. $227 \mathrm{RH}$ ), con lo que éstos no se ven en nada perjudicados por el ejercicio individual de la acción por uno de ellos.

Tal posibilidad es la más lógica y congruente con la voluntad de las partes. Y, además, no está reñida con el carácter indivisible de la hipoteca.

Los arts. $1.860 \mathrm{CC}$ y 122 ss LH lo que prohiben, con carácter general, es que la hipoteca se cancele parcialmente respecto del bien o bienes gravados (es decir, que una vez cumplida, voluntaria o forzosamente, parte de la deuda, la hipoteca deje de gravar parte del bien o alguno de los bienes gravados), pues ello sí perjudicaría a los demás acreedores; pero no impiden que la cuantía garantizada sí se vaya cancelando parcialmente, ya sea a través del cumplimiento voluntario de la prestación ya mediante la ejecución parcial de la hipoteca (permitida por analogía a lo dispuesto en el art. 693 LEC) ${ }^{42}$.

${ }^{40}$ Vid. Roca SAStre, Ramón Ma y RocA-SASTre Muncunill, Luis: Derecho Hipotecario, tomo VIII, Hipotecas, op. cit., p. 267 ss y autores citados por VERDERA SERVER, Rafael: La hipoteca a favor de dos o más acreedores..., op. cit., p. 100-101 y 109 ss.

El art. 227 RH señala: "Se considerarán preferentes a los efectos del art. 131 de la Ley, las cargas o gravámenes simultáneos o del mismo rango que el crédito del actor". A pesar de su referencia expresa al art. $131 \mathrm{LH}$ y al procedimiento judicial sumario, se entiende que este precepto es aplicable a todos los procesos de ejecución.

${ }^{41}$ Vid. Roca SAstre, Ramón $\mathrm{M}^{\mathrm{a}}$ y RocA-SAstre Muncunill, Luis: Derecho Hipotecario, tomo VIII, Hipotecas, op. cit., p. 268.

42 Vid. CORDERO LOBATO, Encarna: "Vencimiento y ejecución de la hipoteca inmobiliaria", en CARrasco Perera, Ángel [et. al.]: Tratado de los Derechos de Garantía, op. cit., p. 722-723 y RocA Sastre, Ramón Ma y RocA-SAStre Muncunill, Luis: Derecho Hipotecario, tomo VIII, Hipotecas, op. cit., p. 267-268. 
Esta cancelación parcial del crédito hipotecario, que no de la garantía al impedirlo los arts. 122 y $125 \mathrm{LH}$, se hará constar en el Registro "por nota al margen de la inscripción hipotecaria" (art, 240, último inciso, RH).

El deudor, tras la ejecución o pago, se verá, por supuesto, liberado frente a ese concreto acreedor mancomunado.

\section{PLURALIDAD DE DEUDORES}

Podemos encontrarnos con el supuesto de que los deudores sean también hipotecantes, en caso de que hayan dado en garantía bienes propios. A esta situación habrá que aplicar también lo dispuesto en el apartado anterior sobre pluralidad de hipotecantes.

Atendiendo ahora únicamente a la existencia de una situación subjetivamente compleja en la posición pasiva de la relación obligatoria, hay que señalar que, de nuevo, habrá que atender al modo en que se haya configurado esa relación: mancomunidad, solidaridad o en mano común.

\section{Cotitularidad en mano común}

Esta configuración exige la actuación conjunta de los sujetos. Por lo tanto, a la hora de realizar la prestación deberán hacerlo todos juntos; todos deberán adoptar las decisiones que afecten a la relación obligatoria; todos serán demandados, en su caso, ante el incumplimiento de la obligación....

\section{Cotitularidad solidaria}

Ante esta forma de organización de la pluralidad subjetiva pasiva es necesario destacar el componente de garantía que puede apreciarse en la constitución de la solidaridad pasiva: con ésta el acreedor se beneficia de una mayor seguridad y facilidad en el cobro al poder exigir el pago a cualquiera de los deudores.

Esta mayor seguridad se acrecienta con la existencia de la hipoteca.

En este caso, como en cualquier otro crédito subjetivamente complejo en la posición pasiva, cualquiera de los deudores podrá cumplir la prestación exigida para la satisfacción del interés del acreedor con efectos liberatorios para todos los coobligados. Y, por su parte, el acreedor podrá exigir la deuda a cualquiera de los deudores. Asimismo, cabe la posibilidad de que entren en juego las excepciones existentes ex art. 1.148 CC.

La posibilidad de cancelación parcial de la hipoteca respecto de los bienes gravados sólo está permitida en nuestro ordenamiento cuando exista tal pluralidad de bienes hipotecados y se haya procedido a la distribución de la responsabilidad conforme a los arts. 119 ss LH. 
Ahora bien, ante la reclamación e incumplimiento por uno cualquiera de los deudores, el acreedor está facultado para ejecutar la hipoteca que garantiza su derecho de crédito.

Cuestión interesante es qué ocurre ante una solidaridad pasiva no uniforme, por existir distintos plazos o condiciones afectantes a cada deudor.

Respecto de las obligaciones en general, se ha indicado que esa parte no vencida no podrá ser reclamada todavía pues el deudor afectado podrá oponer al acreedor una excepción personal y, por otro lado, el resto de deudores podrán oponerle la excepción personal del otro, ex art. 1.148 CC, por la cuantía de la cuota de la que es titular real el deudor afectado por especiales plazos o condiciones.

Pero, en este caso, ante el impago de uno de los deudores que ha visto vencer la obligación antes que a sus coobligados, ¿cabría ejecutar la hipoteca en su totalidad y con eficacia respecto a todos o sólo se ejecutaría parcialmente, en la cuantía de la obligación (o la parte de la misma) vencida?.

Para responder a esta cuestión hay que tener en cuenta el carácter indivisible de la hipoteca (art. $1.860 \mathrm{CC}$ ); el hecho de que cada uno de los deudores está obligado frente al acreedor por el todo; y el juego de las excepciones oponibles en virtud del art. 1.148 CC.

A semejanza de lo que expuse al analizar la solidaridad activa no uniforme, considero que sí es posible la ejecución de la hipoteca ante ese impago de uno de los deudores solidarios. Esta posibilidad es consustancial a la solidaridad, que además, ha sido querida por las partes.

Pero, por efectos de lo dispuesto en el art. $1.148 \mathrm{CC}$, la ejecución sólo podrá efectuarse por el importe de la cuota del deudor que primero ha visto vencida la obligación, pues es la única parte exigible ${ }^{43}$.

Cualquiera de los deudores, o el hipotecante o tercer poseedor del bien gravado, podrá hacer efectiva la deuda antes de proceder a la subasta, tras el requerimiento de pago previsto en el art. 686 LEC. En este caso, se procederá a dar por terminada la ejecución.

Ese pago realizado antes de la subasta o el importe obtenido del remate, en caso de que lo primero no haya tenido lugar, reducirá la cuantía de la deuda (lo que se hará constar mediante nota al margen de la inscripción hipotecaria: art. 240, último inciso, $\mathrm{RH})$, pero la garantía permanecerá íntegra sobre el bien o bienes hipotecados ex arts. $1.860 \mathrm{CC}$ y $122 \mathrm{ss} \mathrm{LH}$, así como las posibilidades de reclamación del acreedor a cualquiera de los deudores solidarios, incluido el primeramente demandado por incumplimiento.

Cuestión que se dirimirá en la relación interna de los deudores será la de los posibles perjuicios que, por el impago del deudor que primero vio vencida la obligación y la posterior ejecución de la hipoteca, hayan surgido para el resto de obligados.

\footnotetext{
${ }^{43}$ Cabe la posibilidad de que la ejecución se amplíe cuando, tras el despacho de la ejecución, venza la obligación para otros deudores (art. 578 LEC).
} 


\section{Cotitularidad mancomunada o parciaria}

En este caso, la deuda aparecerá dividida en tantas partes como deudores haya (art. $1.138 \mathrm{CC})$.

El acreedor sólo estará facultado para reclamar a cada deudor su parte y éstos sólo están obligados respecto de la misma. Cualquier circunstancia modificativa o extintiva sólo tendrá efectos respecto de la concreta deuda parciaria.

El acreedor podrá, ante el impago de uno de los deudores, ejecutar la hipoteca por esa parte del concreto deudor, permaneciendo la hipoteca íntegra sobre el bien o bienes gravados y en garantía de la deuda de los demás obligados mancomunadamente (arts. 1860 CC, 122 ss LH y 227 RH). No será posible la cancelación parcial de la hipoteca (a salvo la aplicación de los arts. 119 ss LH, ante una pluralidad de bienes hipotecados y distribuyéndose entre ellos el crédito), pero sí la de la cuantía asegurada, dejando constancia de la misma mediante una nota marginal en la inscripción de la hipoteca (art. 240 , último inciso, $\mathrm{RH})$.

Por supuesto, el deudor que no paga su deuda y ve ejecutada la hipoteca por la misma, tras la ejecución y satisfacción del interés del acreedor, verá extinguida su responsabilidad y estará liberado frente al acreedor.

\section{VII.- CONCLUSIÓN}

Como se puede apreciar la realidad jurídico-hipotecaria es bastante compleja; y lo es aún más cuando en las distintas posiciones jurídicas concurre una pluralidad de sujetos.

Hay que tener en cuenta los dos tipos de relaciones jurídicas que conviven en estas situaciones: una obligacional (que une al acreedor o acreedores con el deudor o deudores) y otra real (que vincula al acreedor o acreedores con el hipotecante o hipotecantes o, en su caso, los terceros poseedores). De cada una de estas situaciones hay que respetar su naturaleza y régimen esenciales y sus principios rectores y tratar de armonizarlos entre sí. De esta forma se podrán determinar las posibilidades de actuación eficaz de cada uno de los sujetos, especialmente, y por lo que en este trabajo nos hemos centrado, en la fase de exigencia del crédito o cumplimiento de la prestación. 